\title{
Method for the determination of concentration and stable carbon isotope ratios of atmospheric phenols
}

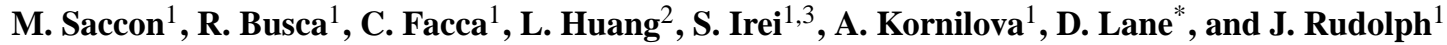 \\ ${ }^{1}$ York University, Centre for Atmospheric Chemistry, 4700 Keele St., Toronto, ON M3J 1P3, Canada \\ ${ }^{2}$ Atmospheric Chemistry \& Technology Directorate, Environment Canada, 4905 Dufferin St., Toronto, ON M3H 5T4, Canada \\ ${ }^{3}$ National Institute for Environment Studies, 16-2 Onogawa, Tsukuba, Ibaraki, 305-8506 Japan \\ * retired from: Environment Canada, 4905 Dufferin St., Toronto, ON M3H 5T4, Canada
}

Correspondence to: J. Rudolph (rudolphj@yorku.ca)

Received: 21 March 2013 - Published in Atmos. Meas. Tech. Discuss.: 28 May 2013

Revised: 22 August 2013 - Accepted: 29 August 2013 - Published: 5 November 2013

\begin{abstract}
A method for the determination of the stable carbon isotopic composition of atmospheric nitrophenols in the gas and particulate phases is presented. It has been proposed to use the combination of concentration and isotope ratio measurements of precursor and product to test the applicability of results of laboratory studies to the atmosphere. Nitrophenols are suspected to be secondary products formed specifically from the photooxidation of volatile organic compounds. XAD- $4^{\mathrm{TM}}$ resin was used as an adsorbent on quartz filters to sample ambient phenols using conventional high volume air samplers at York University in Toronto, Canada. Filters were extracted in acetonitrile, with a HPLC (high-performance liquid chromatography) clean-up step and a solid phase extraction step prior to derivatization with BSTFA (bis(trimethylsilyl) trifluoroacetamide). Concentration measurements were done with gas chromatographymass spectrometry and gas chromatography-isotope ratio mass spectrometry was used for isotope ratio analysis.

The technique presented allows for atmospheric compound-specific isotopic composition measurements for five semi-volatile phenols with an estimated accuracy of $0.3-0.5 \%$ at atmospheric concentrations exceeding $0.1 \mathrm{ng} \mathrm{m}^{-3}$ while the detection limits for concentration measurements are in the $\mathrm{pg} \mathrm{m}^{-3}$ range. Isotopic fractionation throughout the entire extraction procedure and analysis was proven to be below the precision of the isotope ratio measurements. The method was tested by conducting ambient measurements from September to December 2011.
\end{abstract}

\section{Introduction}

Primary emissions of volatile organic compounds (VOC) can undergo photooxidation in the atmosphere to produce numerous compounds, including a range of low volatility substances that contribute to atmospheric particulate organic matter (POM). Nitrophenols are semi-volatile compounds that have been proposed to be formed specifically through the reactions of benzene and alkylbenzenes such as toluene and xylenes (Atkinson, 2000; Forstner et al., 1997; Hamilton et al., 2005; Jang and Kamens, 2001; Sato et al., 2007). Methylnitrophenols have also been reported to be primary emissions in one study (Tremp et al., 1993) and 4-nitrophenol was found to be emitted in vehicle exhaust in small quantities (Nojima et al., 1983). While a range of alkylnitrophenols have been observed in the atmosphere in the particle phase as well as in the gas phase (Cecinato et al., 2005; Morville et al., 2004), the yield of alkylnitrophenols from VOC oxidation and their contribution to secondary organic aerosols (SOA) is highly uncertain. Laboratory studies show a wide range of SOA yields from oxidation of aromatic VOC, and the extrapolation from laboratory experiments, which typically are conducted at ppm levels of precursors, adds significant uncertainty in estimates of ambient POM yields (Forstner et al., 1997; Irei, 2008). Moreover, alkylnitrophenols are semivolatile and it therefore can be expected that they will be found only partly in the airborne particle phase.

It has been proposed that knowing the isotope composition of secondary POM can be used to gain insight into the formation of SOA and differentiate between atmospheric 
processes such as mixing, dilution and chemical processing (Goldstein and Shaw, 2003; Rudolph, 2007); specifically, the use of isotope ratios to substantiate the validity of extrapolation of smog chamber studies to atmospheric conditions (Irei et al., 2011). Stable carbon isotopic compositions of SOA precursors have been previously measured at their emission sources (Czapiewski et al., 2002; Rudolph et al., 2002; Rudolph, 2007; Smallwood et al., 2002) as well as in ambient air (Goldstein and Shaw, 2003; Kornilova, 2012; Rudolph, 2007). Recently, a measurement method for isotope ratios of methylnitrophenols in atmospheric particulate matter (PM) has been established (Moukhtar et al., 2011). In the case of semi-volatile organic compounds (sVOC), this provides merely part of the information needed for comparison with laboratory results since the isotope ratio of sVOC in the gas phase is not necessarily identical to that in the particle phase. However, apart from some laboratory studies of the stable carbon isotope ratios of POM formed by photooxidation of toluene (Irei et al., 2011; Irei, 2008) and very few measurements of some nitrophenols in the particle phase published by Moukhtar et al. (2011), no measurement of the carbon isotope ratio of nitrophenols formed by the photooxidation of alkylbenzenes are known to us. Moreover, there is strong evidence that the majority of nitrophenols exist in the gas phase (Busca, 2010) and measurements of the isotopic composition of nitrophenols in the gas phase have not been published thus far.

Given that nitrophenols are secondary pollutants, their expected concentrations in the atmosphere are difficult to predict, but from the extrapolation of laboratory studies, are projected to be in the several $\mathrm{ng} \mathrm{m}^{-3}$ range (Hamilton et al., 2005; Irei, 2008). However, they often have been found in very low concentrations in the sub $\mathrm{ng} \mathrm{m}^{-3}$ range in PM (Cecinato et al., 2005; Morville et al., 2004; Moukhtar et al., 2011). This results in certain challenges since measuring the compound specific stable carbon isotope composition, which is typically done by gas chromatography coupled to isotope ratio mass spectrometry (GC-IRMS), requires a mass of carbon per compound that is several orders of magnitude higher than the mass needed for concentration measurements (Rudolph, 2007).

Moukhtar et al. (2011) have previously developed a method for the sampling and analysis of the isotope ratio of nitrophenols in PM but also reported that isotope ratios of nitrophenols could only be determined for a very small subset of the samples due to the low concentration in most of the PM samples collected. Since, as mentioned above, a significant part of the total atmospheric nitrophenol concentration is expected to be in the gas phase, measuring the isotope ratio of the sum of gas phase and particle phase nitrophenols would not only reduce uncertainties in the interpretation of measured isotope ratios resulting from distribution between the two phases, but also avoid the problem of acquiring sufficient mass for isotope ratio analysis.
High volume air sampling is an established method for collecting atmospheric trace components in PM from large volumes of air. This sampling method allows having a large sampling volume and flow rate, which is important when analyzing compounds at low concentrations, such as the nitrophenols. However, quartz fiber filters will sample only PM efficiently. There are several applications that use sorbent impregnated filters to collect volatile or semi-volatile compounds from large volumes of air. XAD-4 ${ }^{\mathrm{TM}}$ resin has been previously used as an adsorbent when sampling several atmospheric semi-volatile substances on low volume filters and denuders (Galarneau et al., 2006; Gundel and Lane, 1999). A method was developed using XAD-4 ${ }^{\mathrm{TM}}$-coated high volume filters for sampling for compound-specific concentration and isotope ratio measurements of nitrophenols in both gas phase and PM. A detailed description, several method validation tests as well as examples for ambient measurements are reported and discussed.

\section{Materials and method}

\subsection{Preparation of adsorbent and coating of filters}

For isotope ratio analysis high volume quartz fiber filters $\left(20.32 \mathrm{~cm} \times 25.4 \mathrm{~cm}\right.$ Pallflex ${ }^{\circledR}$ Tissuquartz ${ }^{\mathrm{TM}}$ filters 2500 QAT - PallGelman Sciences) were used, however some tests were conducted using low volume sampling with $47 \mathrm{~mm}$ diameter round filters of the same material as well as annular denuders. Prior to coating, the quartz fiber filters were baked at $1123 \mathrm{~K}$ for $24 \mathrm{~h}$ to remove organic contaminants. The filters were then covered with Teflon sheets and stored in Pyrex containers. Filters and denuders were coated according to standard procedures as described by Gundel et al. (1995), Gundel and Herring (1998), and Galarneau et al. (2006) with some modifications. XAD-4 ${ }^{\mathrm{TM}}, 20-60$ mesh (Sigma Aldrich), was cleaned by sonication for 30 min successively in methanol, dichloromethane and hexane. The slurry was then filtered and dried. The XAD was ground for either $17 \mathrm{~h}$ or $34 \mathrm{~h}$ at $400 \mathrm{rpm}$ in a Retsch planetary ball mill.

Filters were coated by immersing them in a XAD-hexane slurry with a concentration of approximately either 6.5 or $10.5 \mathrm{gXADL}^{-1}$. Before use, the slurry was sonicated for $30 \mathrm{~min}$. Twelve filters, each in a stainless steel mesh holder, were immersed in the slurry 10 times. Following sonication of the slurry for $30 \mathrm{~min}$, the filters were again immersed in the slurry in opposite order 10 times and were then left to dry overnight. To remove excess particles from the filters, the filters were immersed in hexane 10 times, dried, and stored in a Pyrex container until sampling.

\subsection{Sampling}

Samples were collected between September and December 2011 with high volume air samplers (Tisch TE-6001 40 CFM PM-10 retrofitted with a $\mathrm{PM}_{2.5}$ micron head) on the roof of 
the Petrie Science and Engineering building at York University, which is a suburban mixed industrial and residential area in the outskirts of metropolitan Toronto, Canada. The sampling flow rate for high volume air samplers was varied between 0.65 and $1.13 \mathrm{~m}^{3} \mathrm{~min}^{-1}$ and the sampling time was $24 \mathrm{~h}$. The air samplers were calibrated using a TE-5028A calibrator (Tisch Environmental Inc.). Uncertainty of the flow rate, including drift between calibrations was typically around $5 \%$. Low volume air sampling on $47 \mathrm{~mm}$ round filters and denuders had a sampling flow rate of $0.0167 \mathrm{~m}^{3} \mathrm{~min}^{-1}$. Low volume sampling used XAD-coated denuders followed by a $47 \mathrm{~mm}$ round quartz filter and two XAD-coated filters in series or a $47 \mathrm{~mm}$ round quartz filter and two XAD-coated filters in series without denuder. Following sampling, filters were stored in sealed glass jars in a freezer at $253 \mathrm{~K}$.

\subsection{Filter extraction}

The filter and denuder extraction procedure is similar to that described by Moukhtar et al. (2011). Filters were spiked with approximately $4 \mu \mathrm{g}$ each of three internal standards, 2-methylphenol, 2-methyl-3-nitrophenol and 2-methyl-5nitrophenol. The concentrations of 2-methylphenol, 2methyl-3-nitrophenol and 2-methyl-5-nitrophenol in extracts of high volume filter samples without adding internal standards were consistently below the detection limit. For extraction filters were immersed in acetonitrile (pesticide residue analysis grade from Sigma Aldrich) in amber glass jars and sonicated for $15 \mathrm{~min}$. This was followed by filtration with a syringe equipped with a $0.2 \mu \mathrm{m}$ PTFE Chromspec filter and the sonication and filtration procedures were repeated three additional times. All extracts were collected in a round bottom flask and the volume was reduced by rotary evaporation. The sample extract was further blown down to a final volume of approximately $200 \mu \mathrm{L}$ in a $5 \mathrm{~mL}$ conical vial.

HPLC (high-performance liquid chromatography) separation was used to reduce interference from the complex matrix of the sample. The HPLC (HP 1050) was equipped with a Supelco Supelcosil ${ }^{\mathrm{TM}}$ LC-18 column with dimensions $25 \mathrm{~cm} \times 4.6 \mathrm{~mm}$ and $5 \mu \mathrm{m}$ packing size; the detector used was a variable wavelength detector (VWD) set to $320 \mathrm{~nm}$. Solvent flow rate was constant at $1 \mathrm{~mL} \mathrm{~min}^{-1}$, and the solvent gradient began with $100 \%$ deionized Milli-Q water and linearly decreased to $45 \%$ water and $55 \%$ acetonitrile at $10 \mathrm{~min}$. At $15 \mathrm{~min}$, the mobile phase was $15 \%$ water and $85 \%$ acetonitrile and at $30 \mathrm{~min}$ the gradient ended with $100 \%$ acetonitrile. The effluent fraction in the retention time window between 600 and $1020 \mathrm{~s}$, which contained the nitrophenols, was collected and was subsequently partially evaporated at room temperature to remove acetonitrile. It was then acidified to pH 5 with phosphoric acid and passed through a Waters Oasis HLB 3 cc solid phase extraction (SPE) cartridge. Prior to use SPE cartridges were conditioned with $1 \mathrm{~mL}$ of acetonitrile, followed by $1 \mathrm{~mL}$ of Milli-Q water. The target compounds were recovered with approximately $10 \mathrm{~mL}$ of acetonitrile.
This volume was reduced to approximately $0.5 \mathrm{~mL}$ on a rotary evaporator and was further evaporated at room temperature in a $5 \mathrm{~mL}$ conical vial to approximately $50 \mu \mathrm{L}$ under a flow of nitrogen gas at approximately $200 \mathrm{~mL} \mathrm{~min}^{-1} .20 \mu \mathrm{L}$ of a volumetric standard containing heptadecane, octadecane and nonadecane was added to the sample, which was then divided in two approximately equal portions; one for concentration measurements and one for isotopic composition analysis.

\subsection{Analysis}

Prior to injection, samples were derivatized with derivatization grade bis(trimethylsilyl) trifluoroacetamide (BSTFA) from Sigma Aldrich (99.6\% purity). The mixture was stirred for $5 \mathrm{~min}$ at room temperature before transfer to autosampler vials for GC-MS or GC-IRMS analysis. For concentration measurements, $1 \mu \mathrm{L}$ of the sample was injected into a HP 5890 Series II GC with a HP 5972 Series MS detector. Helium was used as a carrier gas and was kept at a constant flow rate of $2 \mathrm{~mL} \mathrm{~min}^{-1}$. A SLB-5ms column $(60 \mathrm{~m} \times 0.25 \mathrm{~mm}$ i.d. $\times 0.5 \mu \mathrm{m}$ film thickness; i.d.: inner diameter) was used. The injection port temperature was $538 \mathrm{~K}$ and the samples were injected splitless with a duration of the splitless mode of $60 \mathrm{~s}$. The initial temperature of the oven was $373 \mathrm{~K}$, which was held for $10 \mathrm{~min}$. The temperature was ramped at $1 \mathrm{Kmin}^{-1}$ until $473 \mathrm{~K}$, held for $1 \mathrm{~min}$ and ramped at $10 \mathrm{~K} \mathrm{~min}^{-1}$ until reaching $553 \mathrm{~K}$ and held for $6 \mathrm{~min}$. Each sample was typically analyzed twice using selective ion monitoring (SIM). The $m / z$ monitored for standards and target compounds is listed in Table 1. Several samples were also analyzed in scanning mode. The GC-MS was calibrated monthly by injecting $1 \mu \mathrm{L}$ standards containing all target compounds and internal standards, ranging in concentration from 1 to $15 \mathrm{ng} \mu \mathrm{L}^{-1}$. Each calibration mixture was run in random order twice.

Samples that contained nitrophenols with concentrations greater than $1 \mathrm{ng} \mu \mathrm{L}^{-1}$ were analyzed with GC-IRMS. This setup (Fig. 1) included an electronically controlled heart split valve in the GC oven that directed the column effluent to the FID when the GC column's background was eluting or to the combustion furnace when target compounds were eluting to minimize contamination of the IRMS. For isotopic composition measurements, $3 \mu \mathrm{L}$ of the derivatized sample was injected onto a SLB- $5 \mathrm{~ms}(60 \mathrm{~m} \times 0.25 \mathrm{~mm}$ i.d. $\times 0.5 \mu \mathrm{m}$ film thickness) column, which had a helium carrier gas flow rate of $1 \mathrm{~mL} \mathrm{~min}^{-1}$. The initial temperature of the oven was $373 \mathrm{~K}$ and held for $10 \mathrm{~min}$. It was then ramped at $0.5 \mathrm{~K} \mathrm{~min}^{-1}$ until $423 \mathrm{~K}$, then ramped at $5 \mathrm{~K} \mathrm{~min}^{-1}$ until $473 \mathrm{~K}$ and held for $1 \mathrm{~min}$. It was finally ramped at $10 \mathrm{~K} \mathrm{~min}^{-1}$ until reaching the final temperature of $553 \mathrm{~K}$ and was held for $6 \mathrm{~min}$. A calibration curve of the GC-IRMS was made in a similar way to GC-MS calibration, only injecting $3 \mu \mathrm{L}$ of standards to increase the mass of carbon and therefore the signal. 


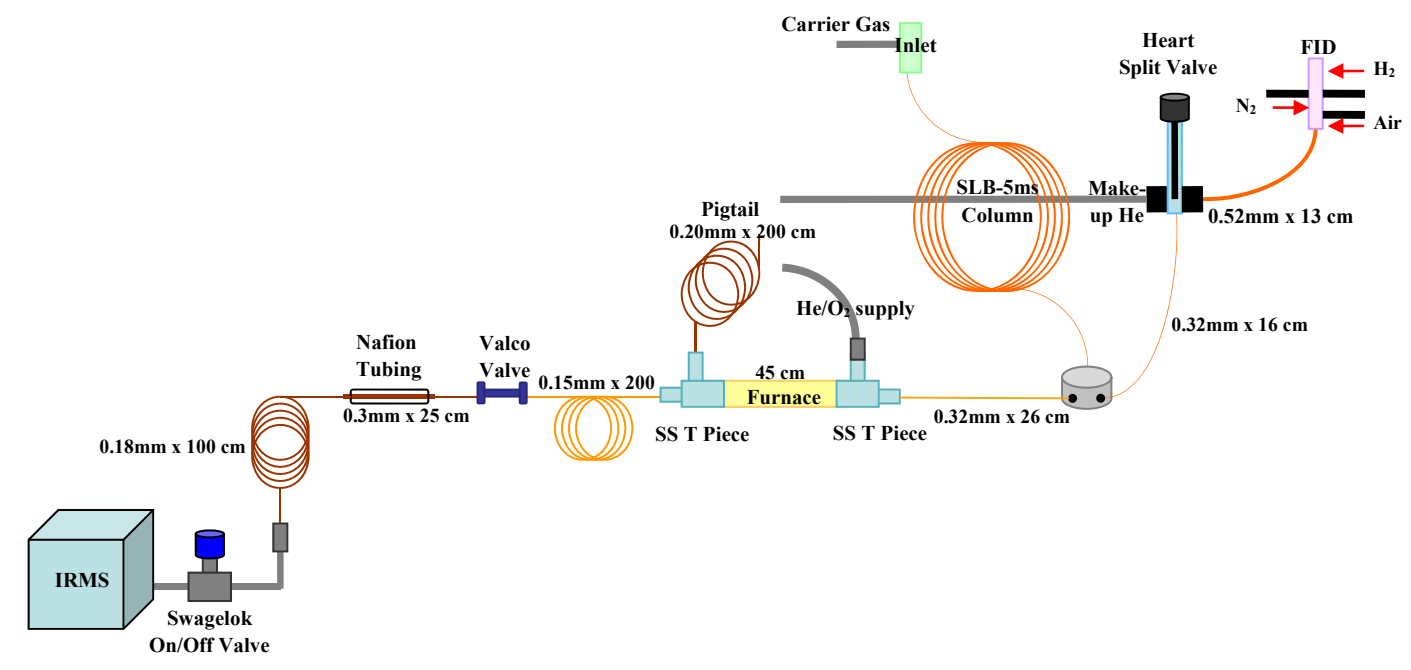

Fig. 1. Schematic of GC-IRMS setup.

Table 1. List of target compounds and standards used and their characteristic masses used for GC-MS SIM detection; all standards were $97-99.8 \%$ purity and were purchased from Sigma Aldrich or Supelco.

\begin{tabular}{llll}
\hline Standard & Abbreviation & $\begin{array}{l}\text { Retention } \\
\text { time } \\
\text { window } \\
(\mathrm{min})\end{array}$ & $\begin{array}{l}\mathrm{m} / z \\
\text { monitored } \\
\text { in SIM }\end{array}$ \\
\hline 2-methylphenol $^{\mathrm{a}}$ & 2-me-ph & $15-55$ & 210,165 \\
4-methylphenol $^{\text {4-methyl-2-nitrophenol }}$ & 4-me-ph & $15-55$ & 210,165 \\
4-nitrophenol $^{\text {2-methyl-3-nitrophenol }}{ }^{\mathrm{a}}$ & 4-me-2-NP & $55-80$ & $225,210,165$ \\
2-methyl-5-nitrophenol $^{\mathrm{a}}$ & 2-me-3-NP & $55-80$ & $225,208,165$ \\
3-methyl-4-nitrophenol & 2-me-5-NP & $55-80$ & $225,210,165$ \\
2-methyl-4-nitrophenol & 2-me-4-NP & $55-80$ & $225,210,165$ \\
2,6-dimethyl-4-nitrophenol & 2,6-dime-4-NP & $80-125$ & $225,210,165$ \\
Heptadecane $^{\mathrm{b}}$ & $\mathrm{C} 17$ & $80-125$ & 85 \\
Octadecane $^{\mathrm{b}}$ & $\mathrm{C} 18$ & $80-125$ & 85 \\
Nonadecane $^{\mathrm{b}}$ & $\mathrm{C} 19$ & $80-125$ & 85 \\
\hline
\end{tabular}

${ }^{a}$ Used as internal standards; ${ }^{b}$ used as volumetric standards.

The GC-combustion furnace interface was similar to that described by Matthews and Hayes (1978) with some modifications as described by Irei (2008). The temperature of the furnace was held at $1223 \mathrm{~K}$ and was used to combust eluting compounds to carbon dioxide and water. Water was removed by passing through a Nafion permeation dryer and the sample then proceeded to the IRMS for analysis. For calibration of the isotope ratio measurements, a carbon dioxide reference gas was injected several times directly for $30 \mathrm{~s}$ periods into the IRMS during the GC runs. The carbon isotope ratio of this carbon dioxide is traceable to the internationally accepted Vienna Pee Dee Belemnite reference (Huang et al., 2013).

Masses 44, 45 and 46 were monitored by the IRMS for the analysis of ${ }^{12} \mathrm{C}^{16} \mathrm{O}_{2}$ and its isotopologues. All peaks were evaluated based on peak boundaries that have been determined using measurements of standard mixtures. Allison's algorithm (1995), which is similar to the one used by Craig (1957), has been applied to correct the ${ }^{17} \mathrm{O}$ interferences in mass 45 . $\mathrm{NO}_{2}$, which also contributes to mass 46 and the addition of the trimethylsilyl (TMS) contribution from derivatization with BSTFA using Eq. (1) were also corrected by following a procedure described by Irei (2008). To correct for the change in carbon isotope ratio due to introducing a TMS group, compounds with known isotope ratios were derivatized and analyzed. The isotope ratio of underivatized phenols was calculated from the isotope ratios of the derivative and the TMS group using mass balance as follows:

$\delta^{13} C_{\text {free }}=\frac{\# C_{\text {deriv }}}{\# C_{\text {free }}} \cdot \delta^{13} C_{\text {deriv }}-\frac{\# C_{\mathrm{TMS}}}{\# C_{\text {free }}} \cdot \delta^{13} C_{\mathrm{TMS}}$.

\section{Results and discussion}

\subsection{Method validation}

GC-MS calibration measurements generally had a better than $5 \%$ relative standard deviation for repeat runs. The uncertainty of the slope of calibration curves for GC-MS measurements was, with very few exceptions, less than $5 \%$. For GC-IRMS measurements, the uncertainty of the calibration was typically between 5 and $10 \%$. The regression coefficient $\left(R^{2}\right)$ of the calibration curves was greater than 0.98 (Table 2). Peak areas for repeat measurements of extracts of ambient filters using GC-IRMS had relative standard deviations of approximately $5 \%$.

Several $20.32 \mathrm{~cm} \times 25.4 \mathrm{~cm}$ and $47 \mathrm{~mm}$ baked quartz fiber filters were analyzed for blank values. Filters used for blank value determination were stored in the same manner as filters used for sampling. Filters were not spiked with internal standards but were extracted according to the described 
Table 2. Slope, error of the slope and regression coefficient from typical GC-MS and GC-IRMS calibration curves of target compounds, internal standards and volumetric standards. Units of slope and error of slope are peak area (in arbitrary units) $\mathrm{ng}^{-1} \mu \mathrm{L}$.

\begin{tabular}{lccclllll}
\hline Compound & \multicolumn{3}{c}{ GC-MS } & & \multicolumn{3}{c}{ GC-IRMS } \\
\cline { 2 - 3 } & $\begin{array}{c}\text { Slope } \\
\left(\times 10^{5}\right)\end{array}$ & $\begin{array}{c}\text { Error of Slope } \\
\left(\times 10^{4}\right)\end{array}$ & $R^{2}$ & & $\begin{array}{c}\text { Slope } \\
\left(\times 10^{6}\right)\end{array}$ & $\begin{array}{l}\text { Error of Slope } \\
\left(\times 10^{5}\right)\end{array}$ & $R^{2}$ \\
\hline 2-me-ph & 6.96 & 1.4 & 1 & & - & - & - \\
4-me-ph & 10.6 & 4.0 & 1 & & - & - \\
4-me-2-NP & 3.19 & 2.1 & 0.99 & & 0.91 & 0.43 & 1 \\
4-NP & 4.61 & 1.6 & 0.99 & & 0.89 & 0.50 & 0.99 \\
2-me-3-NP & 1.95 & 0.6 & 1 & & 1.20 & 0.77 & 1 \\
2-me-5-NP & 3.78 & 1.5 & 0.99 & & 1.63 & 0.84 & 0.99 \\
3-me-4-NP & 2.82 & 1.2 & 0.99 & & 1.48 & 0.67 & 1 \\
2-me-4-NP & 3.46 & 1.3 & 0.98 & & 1.66 & 0.71 & 0.99 \\
2,6-dime-4-NP & 2.97 & 1.3 & 0.98 & & 2.14 & 1.0 & 0.99 \\
C17 & 1.52 & 0.5 & 1 & & 3.40 & 2.2 & 0.98 \\
C18 & 1.50 & 0.4 & 1 & & 4.73 & 3.0 & 0.99 \\
C19 & 1.47 & 0.4 & 1 & & 5.15 & 3.3 & 0.99 \\
\hline
\end{tabular}

extraction procedure. Blank values and detection limits for each of the compounds for both filter sizes are presented in Table 3.

The internal standards used were 2-methyl-3-nitrophenol and 2-methyl-5-nitrophenol and each consistently had recoveries from 50 to $70 \%$. The recoveries of the two internal standards was used for diagnostic testing of the GC-MS and to monitor possible isotopic fractionation using GC-IRMS. Concentrations were calculated using the ratios of the target compound and internal standard peak areas and calibration factors. Blank filters spiked with target compounds and internal standards showed similar recoveries to the internal standards (Table 3). The ratio of the recoveries for the two internal standards was on average 0.95 with an error of the mean of 0.02 . These results are very similar to recoveries reported in detail by Moukhtar et al. (2011) for quartz fiber filters using an identical extraction method. The cresols, 2methylphenol and 4-methylphenol had, on average, low and highly variable recoveries, perhaps due to the high vapor pressure which can result in losses during the volume reduction steps.

Chromatographic separation of the target compounds was verified by analyzing ambient samples in scanning mode of the GC-MS system. Figure 2 shows a typical GC-MS chromatogram that was run in scanning mode. Complete resolution of each of the target compounds and internal standards is observed, apart from 4-nitrophenol and 2-methyl3-nitrophenol and in some cases a small shoulder for the 2-methyl-5-nitrophenol peak. This was confirmed through analysis of the mass spectra. Incomplete resolution of 4nitrophenol and 2-methyl-3-nitrophenol was not an issue for concentration measurements since selective ion monitoring was used and different characteristic peaks were targeted for each of the two compounds. A complete separation of the

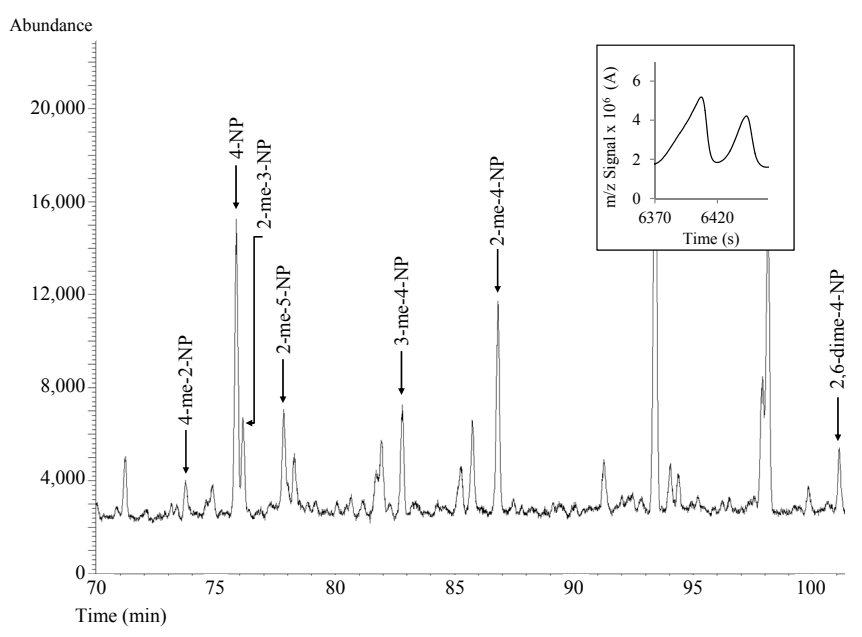

Fig. 2. Fraction of a GC-MS scanning chromatogram of an ambient XAD filter sample. A GC-IRMS chromatogram of the resolved 4$\mathrm{NP}$ and 2-me-3-NP peaks of an ambient filter is shown in the upper right corner.

two compounds was achieved for GC-IRMS measurements by changing the temperature program at the expense of increased duration of the runs (see inlay of Fig. 2). It should be noted that the small shoulder sometimes observed for the 2-methyl-5-nitrophenol peak, one of the internal standards, had no detectable impact on the measured isotope ratio of 2methyl-5-nitrophenol as demonstrated by consistently good agreement between online and offline measurements.

\subsection{Sampling efficiency of XAD-coated filters}

Tests conducted by Busca (2010) showed that filters coated following exactly the procedure described by Gundel and 
Table 3. Averages and standard deviations for phenols from XAD- $4^{\mathrm{TM}}$ blank filter extractions and recoveries for spiked filters.

\begin{tabular}{|c|c|c|c|c|c|c|}
\hline \multirow[t]{2}{*}{ Compound } & \multicolumn{3}{|c|}{ Blank $^{\mathrm{a}}$} & \multicolumn{2}{|c|}{ Detection Limit ${ }^{\mathrm{b}}$} & \multirow[t]{2}{*}{ Recoveries $^{\mathrm{c}}(\%)$} \\
\hline & $\begin{array}{l}\text { Average Mass } \\
\text { of Blank } \\
\text { (ng) }\end{array}$ & $\begin{array}{l}\text { Standard } \\
\text { Deviation } \\
\text { of Blank } \\
(\mathrm{ng})\end{array}$ & $\begin{array}{l}\text { Mass } \\
(\mathrm{ng})\end{array}$ & $\begin{array}{l}\text { High } \\
\text { Volume } \\
\text { Air } \\
\text { Sampler } \\
\left(\mathrm{ng} \mathrm{m}^{-3}\right)\end{array}$ & $\begin{array}{l}\text { Low } \\
\text { Volume } \\
\text { Air } \\
\text { Sampler } \\
\left(\mathrm{ng} \mathrm{m}^{-3}\right)\end{array}$ & \\
\hline 2-me-ph & 3.3 & 2.5 & 7.5 & 0.002 & 0.1 & $13 \pm 8$ \\
\hline 4-me-ph & 7.1 & 3.4 & 10 & 0.002 & 0.1 & $64 \pm 53$ \\
\hline 4-me-2-NP & 4.5 & 5.2 & 16 & 0.003 & 0.2 & $63 \pm 26$ \\
\hline $4-\mathrm{NP}$ & 7.0 & 7.3 & 22 & 0.005 & 0.3 & $70 \pm 3$ \\
\hline 2-me-3-NP & 2.3 & 1.7 & 5.1 & 0.001 & 0.1 & $59 \pm 11$ \\
\hline 2-me-5-NP & 0.48 & 0.36 & 1.1 & 0.0002 & 0.01 & $61 \pm 12$ \\
\hline 3-me-4-NP & 3.9 & 3.9 & 12 & 0.002 & 0.2 & $63 \pm 19$ \\
\hline 2-me-4-NP & 2.5 & 2.7 & 8.1 & 0.002 & 0.1 & $71 \pm 6$ \\
\hline 2, 6-dime-4-NP & 2.4 & 2.0 & 6.0 & 0.001 & 0.1 & $90 \pm 12$ \\
\hline
\end{tabular}

${ }^{\mathrm{a}}$ The extractions were conducted by exactly the same procedure as sample extractions. ${ }^{\mathrm{b}}$ The calculation of blanks and detection limits as atmospheric concentrations are based on volumes typical for $24 \mathrm{~h}$ sampling $\left(1627 \mathrm{~m}^{3}\right.$ for high volume air sampling, and $26 \mathrm{~m}^{3}$ for low volume air sampling). ${ }^{\mathrm{c}}$ Recoveries shown are for blank filters spiked with approximately $4 \mu \mathrm{g}$ of each compound extracted by exactly the same procedure as samples.

Herring (1998) and Galarneau et al., (2006) had a collection efficiency of, on average, around $60 \%$, with significant variability between individual phenols (Fig. 4). Modifications to the method (Table 4) were made to improve nitrophenol collection efficiency. To increase the mass and surface area of $\mathrm{XAD}$ on filters, XAD was ground for a longer time period to decrease average particle size and the XAD concentration of the slurry used in the coating process was also increased.

The vast majority of nitrophenols in ambient air have been found to be present in the gas phase (Fig. 3). This was determined by sampling with denuder filter-pack combinations and filter packs as well as a high volume quartz filter and XAD-coated filters in parallel. On average, $60-90 \%$ of nitrophenols were found to be in the gas phase. The fraction found on the second XAD-coated filter in the filter pack study is consistent with approximately $15 \%$ breakthrough of gas phase nitrophenols through XAD-coated filters. Several tests were conducted to determine the efficiency of the XADcoated filters. Two filters were sampled in series on high volume air samplers, with a stainless steel mesh $(5 \mathrm{~mm} \times 5 \mathrm{~mm}$ grid size, wire thickness about $0.8 \mathrm{~mm}$ ) in between, at a flow rate of 0.65 or $1.13 \mathrm{~m}^{3} \mathrm{~min}^{-1}$. Filters were also sampled in series on low volume air samplers at a standard flow rate of $16.7 \mathrm{~L} \mathrm{~min}^{-1}$. Results are summarized in Fig. 4. The percentage of phenols on the second XAD-coated filter relative to the first filter decreased from, on average, $36 \%$ to around $15 \%$ as a result of the coating method modifications. Breakthrough for low volume air samplers was on average less than $10 \%$, somewhat lower than for high volume samples. This may be due to the lower linear face velocity of 16 versus $41 \mathrm{~cm} \mathrm{~s}^{-1}$ for standard high volume air sampling. However, when sampling on high volume air samplers at
Table 4. Summary of modifications of the filter coating procedure.

\begin{tabular}{lcc}
\hline & $\begin{array}{c}\text { Gundel and Hering (1998), } \\
\text { Galarneau et al. (2006) }\end{array}$ & This Work \\
\hline Grinding time & $17 \mathrm{~h}$ & $34 \mathrm{~h}$ \\
XAD slurry concentration & $6.5 \mathrm{~g} \mathrm{~L}^{-1}$ & $10.5 \mathrm{~g} \mathrm{~L}^{-1}$ \\
Average XAD mass on & $0.09 \pm 0.04 \mathrm{~g}$ & $0.63 \pm 0.1 \mathrm{~g}$ \\
$20.32 \mathrm{~cm} \times 25.4 \mathrm{~cm}$ quartz filter & $0.09 \pm 0.04 \mathrm{~g}$ & $0.63 \pm 0.1 \mathrm{~g}$ \\
\hline
\end{tabular}

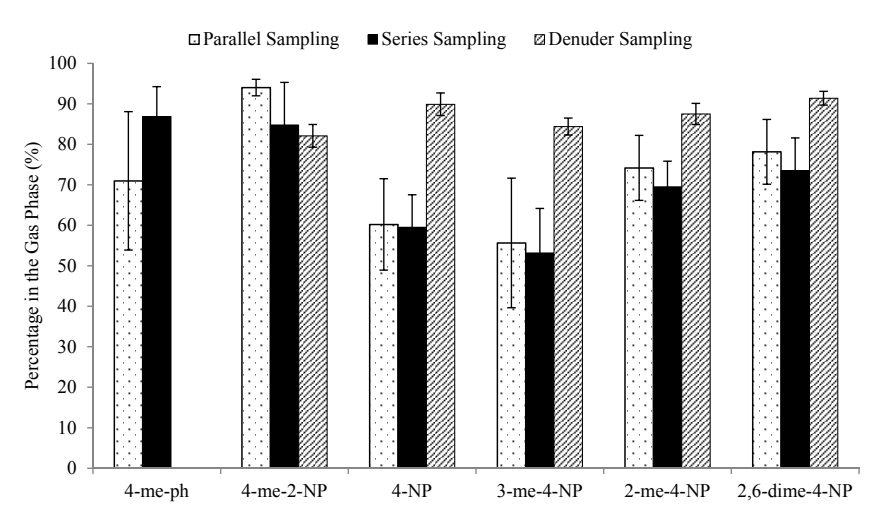

Fig. 3. Partitioning of nitrophenols determined from sampling in parallel and in series using high volume air samplers and denuders.

different flow rates, there was no significant change of sampling efficiency (Fig. 4). A low volume air sampler was used to monitor the efficiency of the XAD-coated filters with a commercially available filter holder that allowed for the sampling of three $47 \mathrm{~mm}$ filters in series. A quartz filter was placed first to remove PM, followed by two XAD-coated filters, which collected the gas phase and blow-off. Approximately $10 \%$ of the total mass collected was found to be on 


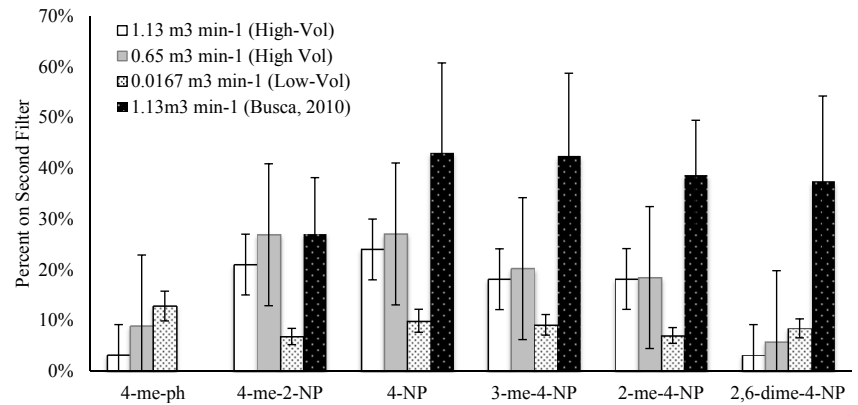

Fig. 4. Efficiency of XAD-coated filters. Error bars represent the error of the mean. The results from Busca (2010) were obtained using filters coated by the method of Gundel and Hering (1998) and Galarneau, et al. (2006). The other results are from this work using a modified coating procedure (Table 4).

the second XAD-coated filter (Fig. 5). This is less than what was observed using the high volume air samplers. The increased breakthrough observed for the high volume air samplers was thought to be attributed to incomplete sealing of the first filter resulting from the stainless steel mesh used to separate the two high volume filters when running breakthrough tests.

\subsection{Isotope ratio measurements}

The carbon isotope ratio of the TMS group was derived from analysis of standards of phenols with known isotope ratios by using carbon isotope mass balance, Eq. (1) (Fig. 6). Averaging over the different compounds, the delta value of the TMS group was found to be $-48 \pm 0.1 \%$.

The result of GC-IRMS isotope ratio measurements for varying masses of phenols injected showed that isotopic composition could be measured accurately within approximately $0.2 \%$ for compounds that had $5 \mathrm{ng}$ or more per $3 \mu \mathrm{L}$ injection (Fig. 7). At lower concentrations, the isotopic composition of each compound showed larger variations. Although there is an indication that for samples containing less than $3.4 \mathrm{ng}$ of phenols, the measured isotope ratios were on average lower than the offline value, this difference is statistically insignificant due to the higher variability of measurements in this mass range. Nevertheless, for injected samples containing more than $1.7 \mathrm{ng}$ of phenols the difference between offline and online values never exceeded $0.6 \%$.

The measured isotope ratio for standards spiked on filters or injected directly into the GC-IRMS were identical within the uncertainty of measurement (Table 5). Offline and online measurements agreed within the uncertainty of the GCIRMS measurements. Furthermore, the isotopic composition of internal standards that were spiked on the filter prior to filter extraction was very similar to offline determined values (Table 6) and the very small differences did not exceed the reproducibility of the measurements.

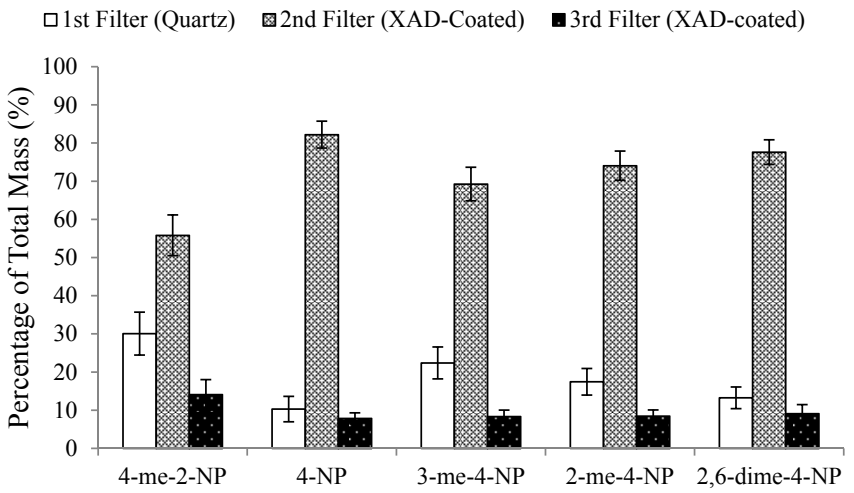

Fig. 5. Efficiency of XAD-coated filters when sampled in series with a front quartz fiber filter. The error bars represent the error of the mean.
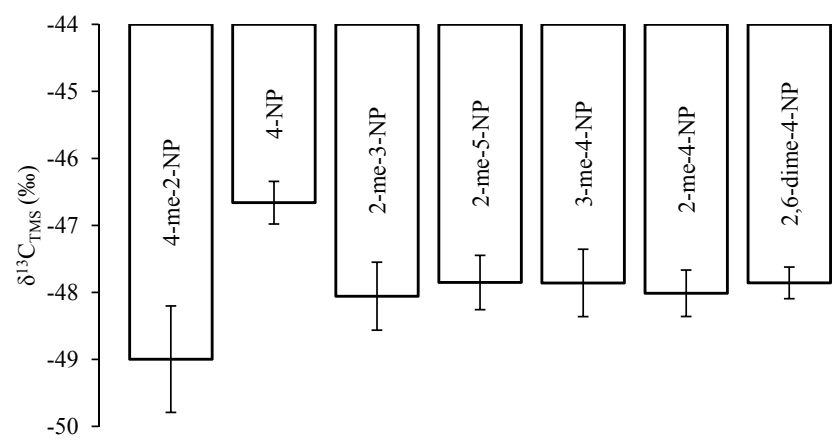

Fig. 6. Isotopic composition of TMS group found by injecting various derivatized compounds. The error bars represent the standard deviations based on an average of five measurements for each phenol.

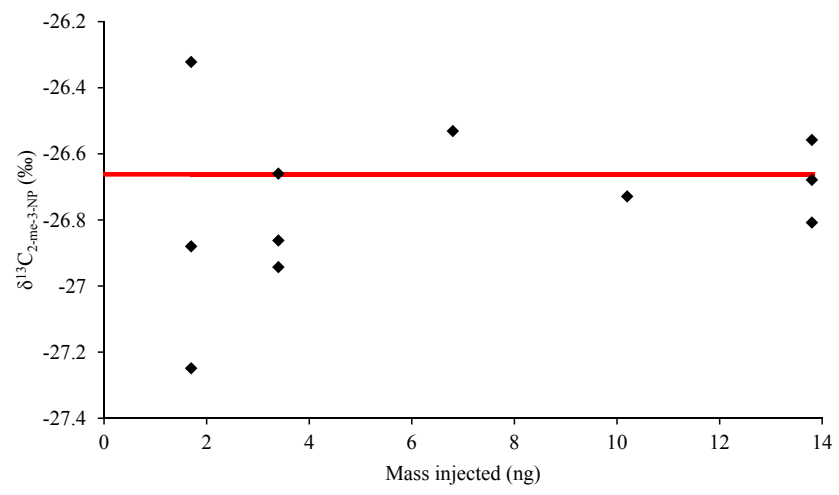

Fig. 7. Changes in the delta value of $2-\mathrm{me}-3-\mathrm{NP}$ as a function of mass injected; the red line indicates the offline value of 2-me-3NP $(-26.7 \%$ ). Average delta values and standard deviations for data points at $1.7,3.4$ and $13.7 \mathrm{ng}$, are $-26.8 \pm 0.5,-26.8 \pm 0.1$ and $-26.7 \pm 0.1 \%$, respectively. 
Table 5. Accuracy of GC-IRMS; online values are averages over 10 points for each compound \pm the error of the mean. Values are for injected masses between 2 and $55 \mathrm{ng}$.

\begin{tabular}{llll}
\hline Compound & $\begin{array}{l}\text { Offline } \\
\text { Value } \\
(\% o)\end{array}$ & $\begin{array}{l}\text { Online Value } \\
\text { (Spiked Filter) } \\
(\% o)\end{array}$ & $\begin{array}{l}\text { Online Value } \\
\text { (Calibration } \\
\text { Standard) } \\
(\% o)\end{array}$ \\
\hline 4-me-2-NP & $-26.9^{\mathrm{a}}$ & $-27.0 \pm 0.3$ & - \\
4-NP & -28.9 & $-28.9 \pm 0.3$ & $-28.5 \pm 0.4$ \\
2-me-3-NP & $-26.7^{\mathrm{a}}$ & $-26.7 \pm 0.2$ & $-26.8 \pm 0.4$ \\
2-me-5-NP & $-27.2^{\mathrm{a}}$ & $-27.3 \pm 0.2$ & $-27.3 \pm 0.3$ \\
3-me-4-NP & $-25.7^{\mathrm{a}}$ & $-25.6 \pm 0.1$ & $-25.5 \pm 0.2$ \\
2-me-4-NP & $-27.4^{\mathrm{a}}$ & $-27.5 \pm 0.3$ & $-27.5 \pm 0.1$ \\
2,6-dime-4-NP & $-29.0^{\mathrm{b}}$ & $-29.0 \pm 0.2$ & - \\
\hline
\end{tabular}

${ }^{\mathrm{a}}$ Measured by Moukhtar et al. (2011); ${ }^{\mathrm{b}}$ measured by Irei (2008).

For 11 filter pairs collected in series, the extract of the second filter had sufficiently high concentrations (0.2$7 \mathrm{ng} \mu \mathrm{L}^{-1}$ ) to allow isotope ratio measurements for 4nitrophenol and 2-methyl-4-nitrophenol. The lower end of the concentrations is below the range for which the GCIRMS isotope ratio measurement results agree with the offline data within $0.2 \%$ (Fig. 4) and therefore the analysis of the second filters may have higher uncertainty and possibly be biased. Nevertheless, the average difference and standard deviation of the differences in the delta values for 4nitrophenol and 2-methyl-4-nitrophenol between the first and second filter was only $0.59 \pm 0.28$ and $0.27 \pm 0.16 \%$, respectively. Using an average breakthrough of around $20 \%$, the maximum bias of isotope ratios for phenols collected on the first filter can be estimated using a simple isotope mass balance to $0.2 \%$ o for 4-nitrophenol and $0.1 \%$ for 2-methyl4-nitrophenol. The reproducibility of isotope ratio measurements was derived from repeat measurement of samples and standards as well as four repeat measurements of two filter extracts. The standard deviations were consistently in the range of $0.2-0.3 \%$ (Table 7 ).

Although the final volume of the extract as well as the recovery somewhat varies, it is possible to estimate the atmospheric phenol concentrations that will give meaningful isotope ratio measurements from typical sample volumes and average recoveries and final extract volumes. Based on an average recovery of $60 \%$, a volume of the final extract (including volumetric standard and derivatization reagent) of less than $100 \mu \mathrm{L}$, a sample air volume of $1627 \mathrm{~m}^{3}(24 \mathrm{~h}$ of high volume sampling) and an $80 \%$ sampling efficiency, it is estimated that isotope ratio measurements can be conducted with a precision of $0.3 \%$ or better for phenols with atmospheric concentrations exceeding $0.1 \mathrm{ng} \mathrm{m}^{-3}$, which is comparable to the lowest concentration of 2-methyl-4-nitrophenol that was successfully analyzed in a set of ambient measurements.
Table 6. Average online delta values of ambient filters spiked with internal standards prior to extraction; the standard deviation for online values $( \pm)$ is based on 23 measurements.

\begin{tabular}{lll}
\hline $\begin{array}{l}\text { Internal } \\
\text { Standard }\end{array}$ & $\begin{array}{l}\text { Offline } \\
\text { Value } \\
(\% o)\end{array}$ & $\begin{array}{l}\text { Online } \\
\text { Value } \\
(\% o)\end{array}$ \\
\hline 2-me-3-NP & -26.7 & $-26.6 \pm 0.2$ \\
2-me-5-NP & -27.2 & $-27.2 \pm 0.2$ \\
\hline
\end{tabular}

Table 7. Average standard deviations of carbon isotope ratios for phenols determined from repeat runs of calibration standards and ambient samples.

\begin{tabular}{ll}
\hline Compound & $\begin{array}{l}\sigma_{\mathrm{avg}} \\
(\% \circ)\end{array}$ \\
\hline 4-me-2-NP & 0.31 \\
4-NP & 0.27 \\
2-me-3-NP & 0.27 \\
2-me-5-NP & 0.19 \\
3-me-4-NP & 0.30 \\
2-me-4-NP & 0.26 \\
2,6-dime-4-NP & 0.31 \\
\hline
\end{tabular}

\subsection{Ambient measurements}

Results for filters sampled using high volume air samplers at York University from September to December 2011, are presented in Figs. 8 and 9. Only isotope ratios for those compounds that had more than $5 \mathrm{ng}$ per $3 \mu \mathrm{L}$ injection and had no overlap in the chromatogram are included. For 4-methyl-2nitrophenol and 3-methyl-4-nitrophenol, only two and three samples, respectively, out of 12 filters, had enough mass for isotope ratio measurements.

Toluene, thought to be the precursor for the methylnitrophenols, was found to have an average ambient isotope ratio of $-24.8 \%$ in Toronto (Kornilova, 2012), with toluene source signatures being approximately -28 to $-27 \%$ o (Rudolph et al., 2002). The average isotopic composition of the nitrophenols measured in this study, is approximately 4-5\%o lighter than that of the precursors. These ambient results are consistent with predictions from laboratory studies (Irei, 2008; Irei et al., 2011) in which the isotope ratio of toluene, as well as that of the sum of all products was monitored over the course of the photooxidation reaction. Similar measurements were made at York University by Moukhtar et al. (2011) for nitrophenols in ambient particulate matter. Although the number of these measurements was very small, the observed delta values of 2-methyl-4-nitrophenol were within a range from -32.9 to $-31.6 \%$ for five samples and are comparable to this study. The difference in isotope ratio between precursor and product, along with evidence from laboratory studies, supports the hypothesis that these 


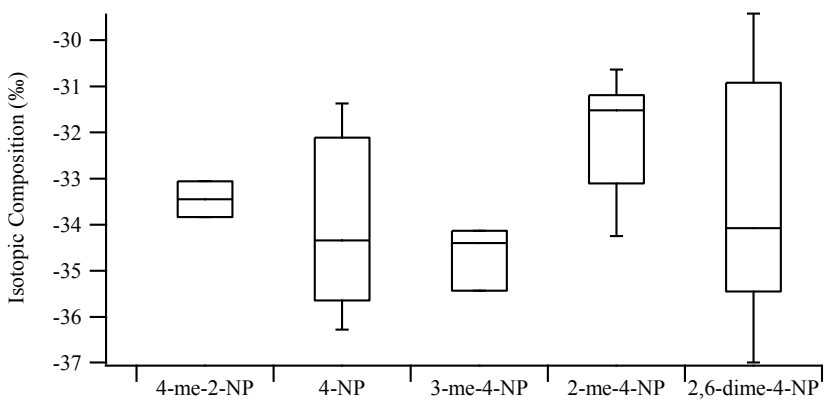

Fig. 8. Box and whisker plot of isotopic composition for the target compounds in ambient air. Error bars represent 90th and 10th percentiles while the upper and lower ends of the box represent the upper (75th) and lower (25th) percentiles; the median is the horizontal line.

compounds are indeed formed through secondary processes and are not primary emissions.

\section{Summary and conclusions}

A method has been developed to determine compound specific carbon isotope ratios of atmospheric phenols in the gas phase and PM. Quartz fiber high volume filters coated by a procedure derived from methodology used to coat low volume filters have been found to be efficient for the collection of nitrophenols in PM and in the gas phase together. The developed sampling, extraction and extract processing procedure created no detectable bias of the carbon isotope ratio. For atmospheric concentrations exceeding $0.1 \mathrm{ng} \mathrm{m}^{-3}$ the estimated accuracy is better than $0.3 \%$.

It has also been validated that concentrations in the range of $\mathrm{pg} \mathrm{m}^{-3}$ can be detected for concentration measurements. Nevertheless, for most atmospheric conditions, low volume filter sampling will be sufficient and only for extremely low atmospheric phenol levels should high volume filter sampling be necessary for concentration measurements. However, with the exception of extremely high levels of atmospheric phenols, low volume filter sampling would not allow to collect sufficient phenol masses for accurate isotope ratio measurements.

The sampling efficiency of XAD-coated filters could be improved to approximately $80-90 \%$ for total atmospheric nitrophenols. Although tests demonstrated that this has no detectable impact on the isotope ratio measurements, this adds uncertainty to concentration measurements. If deemed necessary, using two filters in series increases the total sampling efficiency to better than $95 \%$.

The newly developed methodology has been successfully applied to conduct atmospheric measurements at a suburban location in a major metropolitan area (northern edge of Toronto, Canada). For the most abundant nitrophenols (4-nitrophenol and 2-methyl-4-nitrophenol) accurate isotope

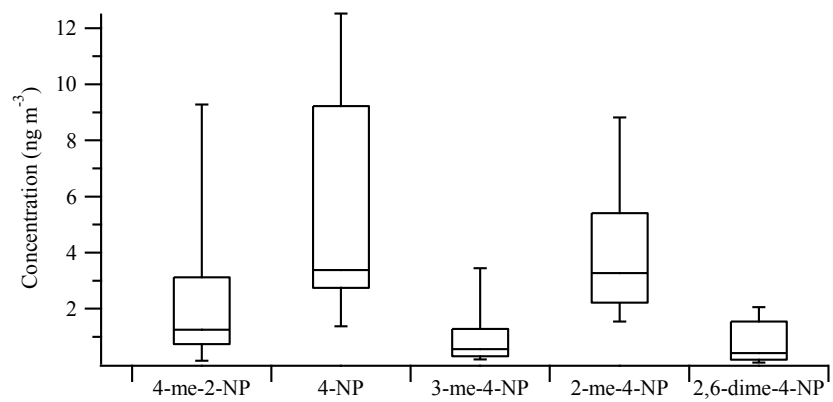

Fig. 9. Box and whisker plot of concentrations for each of the target compounds in ambient air for all samples. Error bars represent 90th and 10th percentiles while the upper and lower ends of the box represent the upper (75th) and lower (25th) percentiles; the median is the horizontal line.

ratio measurements were possible for 21 out of 22 collected filter samples. Ambient results suggest that the phenols analyzed are dominantly formed from secondary processes. For several of the studied phenols the observed atmospheric variability of carbon isotope ratios is more than an order of magnitude larger than the precision of the measurement. The sampling and sample processing method presented can potentially be applied to other atmospheric sVOC and SOA to obtain samples that can by analyzed by GC-IRMS.

In several samples the mass of certain nitrophenols collected was not sufficient for accurate carbon isotope ratio analysis. In principle, it should be possible to reduce the current limit of approximately $0.1 \mathrm{ng} \mathrm{m}^{-3}$ by increasing the volume of air sampled, using injections larger than $3 \mu \mathrm{L}$ for GCIRMS analysis or further reducing the final volume of the extract. However, tests to determine sampling efficiency, recovery and possible bias for such modified procedures have not yet been conducted.

Acknowledgements. The authors acknowledge Darrell Ernst and Wendy Zhang at Environment Canada for technical support in isotope ratio measurements. This research was supported financially by the Natural Sciences and Engineering Research Council of Canada (NSERC) and the Canadian Foundation for Climate and Atmospheric Sciences (CFCAS).

Edited by: P. Herckes

\section{References}

Allison, C. E., Francey, R. J., and Meijer, H. A. J.: Recommendations for the reporting of stable isotope measurements of carbon and oxygen in $\mathrm{CO}_{2}$ gas, in: Proceedings of a consultants meeting held in Vienna, December 1993, IAEA-TECDOC-825, 155-162, International Atomic Energy Agency, Vienna, 1995.

Atkinson, R.: Atmospheric chemistry of VOCs and $\mathrm{NO}_{\mathrm{x}}$, Atmos. Environ., 34, 2063-2101, 2000 
Busca, R.: Method development for the sampling and analysis of atmospheric nitrophenols, M.S. thesis, York University, Toronto, ON, 2010.

Cecinato, A., Di Palo, V., Pomata, D., Scianò, M., and Possanzini, M.: Measurement of phase-distributed nitrophenols in Rome ambient air, Chemosphere, 59, 679-683, 2005.

Craig, H.: Isotopic standards for carbon and oxygen and correction factors for mass-spectrometric analysis of carbon dioxide, Geochim. Cosmochim. Ac., 12, 133-149, 1957.

Czapiewski, K., Czuba, E., Huang, L., Ernst, D., Norman, A. L., Koppmann, R., and Rudolph, J.: Isotopic composition of nonmethane hydrocarbons in emissions from biomass burning, J. Atmos. Chem., 43, 45-60, 2002.

Forstner, H., Flagan, R., and Seinfeld, J.: Secondary organic aerosol from the photooxidation of aromatic hydrocarbons: molecular composition, Environ. Sci. Technol., 31, 1345-1358, 1997.

Galarneau, E., Harner, T., Shoeib, M., Kozma, M., and Lane, D.: A preliminary investigation of sorbent-impregnated filters (SIFs) as an alternative to polyurethane foam (PUF) for sampling gasphase semivolatile organic compounds in air, Atmos. Environ., 40, 5734-5740, 2006.

Goldstein, A. and Shaw, S.: Isotopes of volatile organic compounds: An emerging approach for studying atmospheric budgets and chemistry, Chem. Rev., 103, 5025-5048, 2003.

Gundel, L. and Herring, S. V.: Absorbing filter media for denuderfilter sampling of total organic carbon in airborne particles, Record of invention WIB 1457, Lawrence Berkeley National Laboratory, USA, 1998.

Gundel, L. and Lane, D.: Sorbent-coated diffusion denuders for direct measurement of gas-particle partitioning by semi-volatile organic compounds, in: Gas and particle phase measurements of atmospheric organic compounds, edited by: Lane, D., Gordon and Breach Science Publishers, Canada, 287-332, 1999.

Gundel, L. A., Lee, V. C., Mahanama, K. R. R., Stevens, R. K., and Daisey, J. M.: Direct determination of the phase distributions of semi-volatile polycyclic aromatic hydrocarbons using annular denuders, Atmos. Environ. 29, 1719-1733, 1995.

Hamilton, J., Webb, P., Lewis, A., and Reviejo, M.: Quantifying small molecules in secondary organic aerosol formed during the photo-oxidation of toluene with hydroxyl radicals, Atmos. Environ., 39, 7263-7275, 2005.

Huang, L., Chivulescu, A., Ernst, D., Zhang, W., Norman, A.L., and Lee, Y.-S.: Maintaining consistent traceability in highprecision isotope measurements of $\mathrm{CO}_{2}$ : a way to verify atmospheric trends of $\delta^{13} \mathrm{C}$ and $\delta^{18} \mathrm{O}$, Atmos. Meas. Tech., 6, 16851705, doi:10.5194/amt-6-1685-2013, 2013.

Irei, S.: Laboratory studies of stable carbon isotope ratio of secondary particulate organic matter, Ph.D. thesis, York University, Toronto, ON, 2008.
Irei, S., Rudolph, J., Huang, L., Auld, J., and Hastie, D.: Stable carbon isotope ratio of secondary particulate organic matter formed by photooxidation of toluene in indoor smog chamber, Atmos. Environ., 45, 856-862, 2011.

Jang, M. and Kamens, R.: Characterization of secondary aerosol from the photooxidation of toluene in the presence of $\mathrm{NO}_{\mathrm{x}}$ and 1-Propene, Environ. Sci. Technol., 35, 3626-3639, 2001.

Kornilova, A.: Stable carbon isotope composition of ambient VOC and its use in the determination of photochemical ages of air masses, Ph.D. thesis, York University, Toronto, ON, 2012.

Matthews, D. and Hayes, J.: Isotope-ratio-monitoring gas chromatography-mass spectrometry, Anal. Chem., 50, 14651473, 1978.

Morville, S., Scheyer, A., Mirabel, P., and Millet, M.: A multiresidue method of the analysis of phenols and nitrophenols in the atmosphere, J. Environ. Monitor., 6, 963-966, 2004.

Moukhtar, S., Saccon, M., Kornilova, A., Irei, S., Huang, L., and Rudolph, J.: Method for determination of stable carbon isotope ratio of methylnitrophenols in atmospheric particulate matter, Atmos. Meas. Tech., 4, 2453-2464, doi:10.5194/amt-4-2453-2011, 2011.

Nojima, K., Kawaguchi, A., Ohya, T., Kanno, S., and Hirobe, M.: Studies on photochemical reaction of air pollutants. X. Identification of nitrophenols in suspended particulates, Chem. Pharm. Bull., 31, 1047-1051, 1983.

Rudolph, J.: Gas Chromatography-Isotope Ratio Mass Spectrometry, in: Volatile organic compounds in the atmosphere, edited by: Koppmann, R., Blackwell Publishing Ltd, UK, 388-466, 2007.

Rudolph, J., Czuba, E., Norman, A. L., Huang, L., and Ernst, D.: Stable carbon isotope composition of nonmethane hydrocarbons in emissions from transportation related sources and atmospheric observations in an urban atmosphere, Atmos. Environ., 36, 11731181, 2002.

Sato, K., Hatakeyama, S., and Imamura, T.: Secondary organic aerosol formation during the photooxidation of toluene: $\mathrm{NO}_{\mathrm{x}}$ dependence of chemical composition, J. Phys. Chem. A, 111, 9796-9808, 2007.

Smallwood, B., Philp, R., and Allen, J.: Stable carbon isotopic composition of gasolines determined by isotope ratio monitoring gas chromatography mass spectrometry, Org. Geochem., 33, 149159, 2002.

Tremp, J., Mattrel, P., Fingler, S., and Giger, W.: Phenols and nitrophenols as tropospheric pollutants: emissions from automobile exhausts and phase transfer in the atmosphere, Water Air Soil Poll., 68, 113-123, 1993. 